\title{
HUELLAS DE DISIDENCIA HOMOERÓTICA EN EL UNICORNIO DE MANUEL MUJICA LAINEZ ${ }^{1}$
}

\author{
Jorge Luis Peralta \\ Universidad Nacional de La Plata - CONICET \\ jperalta@fahce.unlp.edu.ar
}

\section{RESUMEN / ABSTRACT}

A través de la narración en primera persona del hada Melusina -figura clave del imaginario medieval- en su novela El unicornio (1965) Mujica Lainez subvierte patrones sexo-genéricos dominantes e incorpora formas de deseo que, de haber sido localizadas en un contexto argentino y contemporáneo al momento de la escritura, hubieran resultado particularmente problemáticas. La reconstrucción de personajes y motivos medievales constituye, en numerosos pasajes, una estrategia para articular posibilidades eróticas que escapaban a la rígida moral impuesta en la Argentina de mediados de la década de 1960.

Palabras ClaVE: Mujica Lainez, novela, Melusina, disidencia homoerótica, Medioevo francés.

By means of a first person narration led by the fairy Melusina-key figure in the medieval imaginary - in his novel El unicornio (1965) Mujica Lainez subverts dominant sex-gender patterns and incorporates desire forms that, had they been localized in an Argentinean and contemporary context at the moment they were written, could have resulted particularly problematic. Thus, the reconstruction of medieval characters and motifs arises as a strategy to articulate erotic possibilities that dissent from dominant rigid morals in Argentina during the mid 1960s.

KEY WORDS: Mujica Lainez, novel, Melusina, homoerotic dissidence, French Middle Ages.

1 Este trabajo forma parte del proyecto de investigación FEM2011-24064 del programa de I+D+i del Ministerio de Economía y Competitividad de España. 
Durante la década de 1950, Manuel Mujica Lainez ganó notoriedad -y un lugar de indudable relevancia en el campo literario argentino- a través de la publicación de una serie de piezas narrativas que tenían a Buenos Aires como principal foco temático. Mientras los cuentos de Aquí vivieron. Historia de una quinta de San Isidro (1949) y Misteriosa Buenos Aires (1950) respondieron al esfuerzo por dotar a la ciudad de una mitología propia, las novelas de la denominada "saga porteña” retrataron el antiguo esplendor y la inexorable decadencia de la clase alta, cuyo poder se había ido debilitando ante el avance de nuevas fuerzas políticas y sociales ${ }^{2}$. Tras la publicación, en 1957, de la última novela de esta saga, Invitados en el Paraíso, la obra de Mujica Lainez dio un giro espacial y temporal cristalizado en una trilogía de novelas "históricas” de ambientación europea: así, Bomarzo ofrecía una minuciosa -y bien documentada- reconstrucción del Renacimiento italiano, mientras que El unicornio (1965) y El laberinto (1974) hacían lo propio con la Francia medieval y el Barroco español, respectivamente ${ }^{3}$. Este "gesto cosmopolita" fue objeto de severas críticas por cuanto suponía un abandono del tema nacional y, más cuestionable aún, la búsqueda de una proyección universal a partir de una empresa narrativa desvinculada de toda problemática social (Laera 2005). Estéticamente, además, Mujica Lainez no se interesaba por la experimentación formal; su prosa manifestaba, por el contrario, una clara filiación con modalidades y tradiciones extemporáneas (Zangrandi 2011). Recargado y preciosista, el estilo del autor parecía estar muy lejos de las preocupaciones actuales de la literatura de la época; en este sentido, las voluminosas novelas localizadas en Europa no hicieron más que ratificar, para cierta crítica, su anacronismo y escaso compromiso político. Paradójicamente,

\footnotetext{
Sobre esta saga, pueden consultarse, entre otros, los trabajos de Villena, Frances Vidal, Schanzer y Cerrada Carretero.

Se ha discutido si esta trilogía y otras novelas del autor pueden adscribirse o no al género de la "novela histórica”. Nogueras, en relación con El unicornio, sostiene que no vale la pena "entrar en la cuestión de si [...] es una novela histórica en el sentido tradicional, o una 'nueva novela histórica' o 'novela histórica posmoderna'. [...] La debilidad del concepto de verdad, las nuevas corrientes historiográficas y la crítica epistemológica de la historia, la desorientación del sujeto posmoderno y la crisis de las identidades, la inestabilidad de lo real o la dilución de las fronteras entre los géneros están harto presentes en esta novela" (479). Un interesante análisis de la narrativa histórica de Mujica Lainez y su relación con la posmodernidad se encuentra en el libro de Caballero, donde si bien se excluye El unicornio hay un extenso análisis de Bomarzo.
} 
este rechazo no fue compartido por el público, que convirtió en best-seller cada nueva entrega de la trilogía.

Para Alejandra Laera, la frivolidad que Mujica Lainez efectivamente cultivó era muy diferente de la que sus detractores le atribuían. No se trataría, según la investigadora, de una actitud ligada a lo superficial o insustancial, sino de una pose despreocupada y atrevida que le servía "para aludir a ciertos motivos recurrentes en sus libros, ciertos motivos vinculados con la sexualidad y los deseos, de los cuales, acaso, resultara poco sencillo hablar abiertamente" (13). En una línea similar, Leopoldo Brizuela propone que

la clasificación tradicional de 'novelas históricas', que una crítica distraída y en general reticente aplicó a esta nueva serie, disimuló todo lo que el proyecto de Mujica Lainez tiene en sí mismo de original y revolucionario, entre otras cosas, por la consideración de la homosexualidad en marcos premodernos, acompañada de una búsqueda de elementos formales anacrónicos que permitieran expresarla (80).

Las lecturas tradicionales de la obra de Mujica Lainez, en general y de esta trilogía en particular han evitado explorar en profundidad la vertiente temática relacionada con el género, el erotismo y la sexualidad. Si bien Marcos Zangrandi (s/d) señala que en los últimos años se ha iniciado una significativa revisión que incluye aproximaciones a estos temas, lo cierto es que todavía escasean los análisis emplazados en una óptica gay o queer ${ }^{4}$. En relación con la novela que nos ocupa, El unicornio, no existe, en mi conocimiento, ningún estudio centrado en aspectos de género o sexualidad, lo que no puede menos que llamar la atención, dada la relevancia que adquieren en la trama ${ }^{5}$. A mi juicio, la recreación de personajes y motivos del Medioevo constituye, en numerosos

\footnotetext{
Como excepciones, cabe citar el análisis de Prinkey de la nouvelle "El retrato amarillo" (1956) y el capítulo de la Historia de la literatura gay en Argentina, en el que Adrián Melo revisa, sin ánimo de exhaustividad, algunas representaciones de la homosexualidad en las novelas más conocidas de Mujica Lainez, entre ellas Bomarzo y El unicornio (171-176).

En general, los estudios sobre la novela se consagran a cuestiones temáticas y formales. Un ejemplo contundente de la omisión del aspecto homoerótico se encuentra en el meticuloso análisis estructural de Cerrada Carretero, para quien la fuerza temática más importante de la obra es "la realización del hombre en cuanto tal y de las acciones que emprende" (402). Melusina, según este investigador, "desea realizarse como hada-protectora de su propia estirpe y como mujer físicamente, tras la condena impuesta por su madre" (403). Sin embargo, en numerosos pasajes, la narradora deja en claro que su mayor anhelo de su "vida” fue conseguir el amor de Aiol. Ver, por ejemplo, el diálogo que mantiene con Oberón
} 
pasajes de la novela, una estrategia para articular posibilidades eróticas que escapaban a la rígida moral dominante en la Argentina de mediados de la década de 1960. Mi lectura apunta, por este motivo, a rastrear las huellas de disidencia homoerótica que Mujica Lainez diseminó en la obra y que pueden valorarse como auténticos gestos de subversión en un contexto hostil, en general, a la diversidad ${ }^{6}$.

Antes de avanzar en el análisis, conviene precisar el significado y el alcance de la noción de "disidencia homoerótica", en la que convergen la propuesta de Jonathan Dollimore (1991) de "disidencia sexual" [sexual dissidence] y el concepto de "homoerotismo", de uso frecuente en la investigación historiográfica $\mathrm{LGTB}^{7}$. De acuerdo con Dollimore, las concepciones del ser, del deseo y de la transgresión que figuran en los lenguajes, ideologías y culturas dominantes son resistidas de diversas maneras (21). La disidencia sexual constituye una forma posible de resistencia articulada en términos de género, que desestabiliza, reiteradamente, la oposición entre lo dominante y lo subordinado: "la literatura, las historias y las subculturas de la disidencia sexual, aunque durante mucho tiempo ausentes de los debates (literarios, psicoanalíticos y culturales) resultan remarcablemente iluminadores para ellos”. Uno de los argumentos principales de este crítico sostiene que la

en el capítulo VI (Mujica Lainez 258-261) o la extensa reflexión al respecto al comienzo del capítulo VIII (311).

6 Algunos críticos han mencionado la presencia del tema homoerótico, sin incidir extensamente en él. Por ejemplo, Schanzer describe el viaje de Melusina y Aiol como "una peregrinación no exenta de matices homosexuales y bisexuales" (87). Puente Guerra, por su parte, comenta que en El unicornio, Mujica Lainez "usa el tema del cambio del sexo para imbuir la historia con claras connotaciones homosexuales" (269), mientras que Cerrada Carretero señala "la homosexualidad y la belleza física masculina” entre los temas que aparecen en la obra (401). Finalmente Melo (2011: 173-175), que sí analiza con mayor extensión las configuraciones del homoerotismo en la narrativa del escritor, en el caso de El unicornio solo ofrece una síntesis argumental y valora la novela como más luminosa que Los ídolos (1953), pero no menos trágica (173-175).

Entre los numerosos ejemplos pueden mencionarse Love Between Women. Early Christian Responses to Female Homoeroticism (1996) de Bernadette J. Brooten; Homoeroticism in the Biblical World: A Historical Perspective (2004) de Martti Nissinen; Among Women: From the Homosocial to the Homoerotic in the Ancient World (2009) de Nancy S. Rabinowitz y Lisa Auanger y Homoeroticism in Imperial China: A Sourcebook (2013) de Marc Stevenson y Wu Cuncun.

En una línea similar, el concepto de “discrepancia sexual” [sexual dissent] de Lisa Duggan "invoca un conjunto de discursos, políticas y prácticas, y establece una conexión 
disidencia no solo sería reprimida (coercitiva e ideológicamente) por lo dominante, sino, en cierta manera, producida por ello, consolidando, así, los poderes que aparentemente desafía (26-27) ${ }^{9}$.

"Homoerotismo" define, siguiendo a Félix Rodríguez, una "relación sexual entre personas del mismo sexo que no supone el fundamento de una entidad social particular y específica" (203). Desprovisto de una impronta "identitaria”, lo homoerótico abarca un amplio espectro de relaciones entre personas del mismo sexo y resulta una noción especialmente pertinente para aproximarse a realidades socio-sexuales del pasado ${ }^{10}$. David Halperin ha señalado la dificultad que supone, para los historiadores de la sexualidad, "recuperar los términos en los cuales se constituyeron efectivamente las experiencias eróticas de individuos pertenecientes a sociedades antiguas [así como] medir y valorar las diferencias entre esos términos y los que empleamos actualmente" (63). La misma dificultad se plantea, a mi juicio, en el análisis de textos literarios escritos en (o sobre) periodos históricos en los cuales las categorías sexo-genéricas eran muy diferentes o, incluso, ni siquiera existían. La noción de "homoerotismo" evita, en este sentido, el riesgo de un uso anacrónico de términos como "homosexual” o “queer”. La

entre expresiones sexuales, políticas de oposición y reclamos por el espacio público. Dado que las representaciones sexuales construyen identidades (y no solo reflejan identidades preexistentes), la restricción y regulación de la expresión sexual es una forma de represión que apunta a las minorías sexuales y a los inconformistas del género” (5). Las traducciones de textos originales en inglés pertenecen al autor.

$9 \quad$ En el campo de la literatura, Dollimore distingue cuatro "estrategias de discurso inverso" [reverse-discourse strategies], relacionadas con los binarismos (especialmente, natural/no natural) que organizan y definen a los sujetos "desviados", y cuya subversión del orden establecido varía según el modo en que los autores plantean esos binarismos. André Gide, por ejemplo, apuesta por "participar en el término dominante más que en el inferior: 'nosotros somos naturales también'. Esto implica una lucha dentro de los mismos conceptos que excluyen lo subordinado, una lucha que es simultáneamente una apropiación y una transformación de esos conceptos" (226).

$10 \quad$ Sedgwick explica que si bien los comportamientos sexuales y las identidades conscientes que denota el término "homosexual", acuñado a finales del siglo XIX, ya poseían una larga y rica historia, "lo nuevo de las postrimerías del siglo pasado fue la delimitación de un esquema mundial por el cual, del mismo modo que a todas las personas se les había asignado forzosamente un género masculino o femenino, también se consideraba necesario asignar una identidad homo o heterosexual, una identidad binarizada llena de implicaciones, por confusas que fueran, incluso para los aspectos menos ostensiblemente sexuales de la existencia personal" (12). 
“disidencia homoerótica” debe comprenderse como una forma de resistencia (constitutiva) al orden establecido, vinculada específicamente con relaciones sexuales y/o afectivas entre sujetos del mismo sexo, pero que no implica, necesariamente, la articulación de una "identidad”.

La obra de Mujica Lainez abunda en ejemplos de esta forma de disidencia. Brizuela señala que quien quisiera estudiar el tema "debería detenerse en, por los menos, un ochenta por ciento de sus obras" (81), afirmación que corrobora Puente Guerra al relevar los principales personajes homoeróticos (femeninos y masculinos) que aparecen en la narrativa del autor (268-269). En una entrevista con María Esther Vázquez, Mujica Lainez declara que recién en Sergio (1976) se atrevió "a contar una historia más abiertamente homosexual" (118), aunque ya desde Los ídolos (1953) se manifiestan tensiones significativas en torno del secreto (homo)sexual, e incluso Cecil, novela semiautobiográfica publicada en 1972, alude sutilmente a los amores masculinos del escritor desde la perspectiva excepcional de un perro ${ }^{11}$. Otro texto significativo por su exploración del homoerotismo, El retrato amarillo $(1956)^{12}$, fue abandonado por Mujica Lainez a instancias de su mujer, Ana de Alvear: "le di a leer a Anita unas páginas y ella me dijo: ‘¿Cómo te metés con ese tema, con esas cosas tan ambiguas?'” (Mujica Lainez en Vázquez 111). Conviene señalar, sin embargo, que a pesar de su centralidad y presencia constante, la disidencia homoerótica no es la única que articula la obra del autor, donde se aprecian muchas otras formas de transgresión a la sexualidad normativa: incesto, fetichismo, onanismo, travestismo. Siempre dentro de ciertos parámetros de decoro y "buen decir”, Mujica Lainez pudo ofrecer visiones alternativas sobre el género y la sexualidad, desafiando, de ese modo, los límites de la moral convencional. Así se advierte, por ejemplo, en el capítulo

11 Entre las obras de temática más o menos explícitamente homoerótica cabe mencionar los cuentos "El cofre (1648)" y "La viajera (1840)", incluidos en Aquí vivieron. Historia de una quinta de San Isidro, 1583-1924 (1949) y "Las ropas del maestro (1608)", "El amigo (1808)", "Memorias de Pablo y Virginia (1816-1852)" y "El salón dorado (1904)", de Misteriosa Buenos Aires (1951), así como las novelas La casa (1954), El retrato amarillo (1956), Bomarzo (1967), Crónicas reales (1967), El laberinto (1974), El viaje de los siete demonios (1974), Los cisnes (1977), El gran teatro (1979), El escarabajo (1982) y Un novelista en el Museo del Prado (1984).

12 Según Puente Guerra, Mujica Lainez empezó a escribir esta obra a comienzos de la década de 1950, pero recién se publicó en 1956 en la revista Ficción (270). No volvió a editarse hasta 1993 en la antología Cuentos inéditos (1993) y, en forma independiente, en un volumen aparecido en España en 1994. 
de Los viajes de los siete demonios (1977) consagrado a Asmodeo, el diablo de la "lujuria", quien hace incurrir en este pecado a un hombre de férreos principios católicos ${ }^{13}$. Las imágenes que fragua Asmodeo para "pervertir" a Monsieur Philippe Lonvilliers de Poincy ("el inflexible, el intolerante, el perfecto") configuran un tapiz de auténtica diversidad erótica que cuestiona los binarismos (femenino/masculino, homosexual/heterosexual) y revela, en clave irónica, la fluidez de los deseos, los géneros y las identidades ${ }^{14}$.

En el caso de El unicornio, dos operaciones, diferentes y a la vez complementarias, definen la incorporación del homoerotismo: por una parte, la distancia espacial y temporal favorece el tratamiento de cierta heterodoxia sexual y de género ${ }^{15}$; por otra parte, los rasgos negativos que distinguen los personajes y relaciones homoeróticas parecen remitir no tanto al universo reconstruido en la novela como al contexto en que fue escrita. Dicho de otro modo, la coartada del distanciamiento da libertad al autor para jugar con identidades, deseos y placeres poco o nada ortodoxos, al tiempo que se constata la existencia de un límite o tabú que frustra la concreción del vínculo sexual y afectivo entre varones, en lo que puede entenderse como una proyección actual de la situación de los homosexuales en Argentina. Se podría debatir, en efecto, si las "innumerables desdichas" que al decir de Adrián Melo (171) padecen los hombres que aman a otros hombres en la narrativa de Mujica Lainez son el resultado de una representación estereotipada o bien el único

13 El episodio transcurre en las Antillas a la altura de 1647. Conviene recordar que la obra, a medio camino entre el cuento y la novela, narra los viajes que realizan los siete demonios del título al mundo de los humanos, con el objetivo de "captar" con su pecado correspondiente a alguno de ellos. Cada episodio se desarrolla en coordenadas temporales y especiales diferentes.

14 Se destaca además, el carácter teatral/performativo que anima ciertas expresiones de disidencia (homo)sexual, ya que Asmodeo “actúa” para De Poincy un variado espectro de personalidades heterodoxas (de origen histórico y/o literario): "De un brinco, se situó en el medio del aposento, encuadrado, como un teatrillo, por las columnas de la cama, y allí, sucesivamente, retozando con erudita holgura por encima de los siglos y de los países, fue una geisha del Japón, un efebo espartano, una hetaira de Corinto, un travesti brasileño, Safo de Lesbos, el amante de Lady Chatterley, una Emperatriz de Bizancio, el Príncipe de los Lirios de Creta, una prostituta de Hamburgo, un paje del Renacimiento, las dos majas de Goya, Lord Alfred Douglas, un hada de 'Las Mil y Una Noches', un hermafrodita de cualquier parte, Don Juan y la Bella Otero” (Mujica Lainez, El viaje 211).

15 Sobre las diversas estrategias utilizadas por los escritores para retratar realidades gays y lésbicas, véase Llamas (132-139). El crítico destaca que el "emplazamiento anacrónico" estaría asociado a la sensación de una imposibilidad en el presente (133). 
tipo de testimonio que podía brindar un escritor como él, cuya imagen pública simultáneamente exhibía y escamoteaba la homosexualidad, pero que nunca protagonizó un coming out (Brizuela 81).

Al margen de los reparos inherentes a su posición social, la visión trágica que acompaña sus figuraciones literarias del homoerotismo bien puede comprenderse como un eco textual de una realidad efectivamente adversa. La persecución de los homosexuales se había iniciado de forma sistemática en 1946 bajo el mandato de Juan Domingo Perón ${ }^{16}$. Hasta ese momento, no había existido una legislación específica y la sociabilidad homoerótica había podido desarrollarse con cierto margen de autonomía, como demuestra la investigación de Pablo Ben (2009). Los principales desencadenantes de la consolidación de una subcultura homosexual en la ciudad de Buenos Aires deben buscarse en las profundas transformaciones espaciales y sociales que se venían gestando desde la década de los treinta. El paso de la ciudad de "gran aldea” a metrópoli cosmopolita, así como nuevas formas de sociabilidad fundadas sobre una ideología familiarista y heterosexista contribuyeron a la progresiva diferenciación de los homosexuales como un grupo “aparte”. De acuerdo con Anabella Gorza, el discurso médico de la época trazó fronteras claras entre una sexualidad deseable -basada en un modelo de género binario y heterosexual- y una sexualidad indeseable y abyecta, en la que se incluían todas aquellas identidades que no respondían al modelo "correcto": homosexuales -o "amorales"- en primer lugar, pero también lesbianas y travestis e incluso "personas que pueden definirse como varones o mujeres pero con características anatómicas o comportamientos que no corresponden a los asignados socialmente a su género" (199). La preocupación que generó la homosexualidad tanto al Estado peronista como a numerosas instituciones normativas -entre ellas la medicina, la Iglesia o la prensa- y que derivó en medidas concretas contra sujetos que se desviaban de la norma, constituye un ejemplo de lo que Jeffrey Weeks denomina "pánico moral”: "los pánicos morales son ráfagas de angustia cultural y temor social que, por lo general, apuntan a una condición o a una persona o grupo de personas que se definen como una amenaza para los valores y supuestos sociales aceptados" $(188)^{17}$.

16 Sobre la situación de los homosexuales durante el peronismo, resulta indispensable el trabajo de Ben y Acha. Ver también Guy y la autobiografía de Malva.

17 El análisis de Rubin sobre el "pánico moral” que se produjo en Estados Unidos, también en la década de 1950, respecto de las "comunidades eróticas disidentes", resulta muy iluminador, más allá de las obvias diferencias contextuales: "desde finales de los años cuarenta 
El principal instrumento de persecución de los homosexuales fue el Reglamento de Procedimientos Contravencionales dictado por el decreto $\mathrm{n}^{\circ}$ 10.868/46 del Poder Ejecutivo, que autorizaba a la policía a "sancionar y aplicar edictos que reprimían actos no previstos por las leyes en materia de seguridad, entre ellos la homosexualidad, que no existía como delito en el Código Penal” (Sebreli 318$)^{18}$. El edicto más utilizado era el de "Escándalo", especialmente a través del artículo $2^{\circ}$, inciso $\mathrm{H}$, que condenaba a "personas de uno u otro sexo que públicamente incitaren o se ofrecieren al acto carnal” (Jáuregui 164). Dicho decreto se aplicaba de forma exclusiva contra homosexuales y prostitutas, "y nunca a varones heterosexuales que provocaran a mujeres en la vía pública" (Sebreli 318). La política represiva instaurada por el gobierno peronista y continuada por mandatos posteriores obligó a reforzar los lazos de solidaridad y las estrategias de "resistencia” de quienes no respondían a los patrones sexo-genéricos impuestos. En la escena cultural, la actividad desarrollada por Ediciones Tirso -y en menor medida, por la revista y la editorial Sur- debe entenderse como un esfuerzo sutil, pero contundente, por desafiar la homofobia del periodo a través de la difusión de textos de temática homoerótica extranjera y argentina. Las traducciones de importantes títulos de la literatura homófila -sobre todo francesa-y la publicación de las novelas pioneras de Renato Pellegrini, contribuyeron a crear un espacio anómalo en el campo literario y cultural argentino, incorporando voces y cuerpos que habían estado, hasta entonces, al margen de lo legítimamente representable ${ }^{19}$.

Si bien en la Argentina de los años sesenta se produjeron, como explica Isabella Cosse, una serie de cambios importantes respecto de las convenciones sexuales de décadas anteriores, eso "no significó la expansión irrestricta de la libertad sexual. Así lo mostraba la centralidad que mantenía la pauta heterosexual, la sexualidad unida a la afectividad y las desigualdades de género en relación con la moral sexual" (206). Las cruzadas moralizadoras

hasta principios de los sesenta, las comunidades eróticas cuyas actividades no encajaban en el sueño americano de la postguerra fueron objeto de intensa persecución. Los homosexuales fueron, junto con los comunistas, objeto de las purgas y cazas de brujas en todo el país" (118-119).

18 Según Sabsay, "estos edictos facultaban a la policía para determinar discrecionalmente el carácter de las conductas sancionables que no estaban catalogadas en los códigos penales y civiles nacionales y proceder a la privación de la libertad de las personas por 48 horas sin causa imputable, así como proceder al arresto por más tiempo cuando la misma persona imputaba alguna causa sin mediación jurídica de ningún tipo" (63).

19 Para un desarrollo más amplio de la actividad editorial de Tirso, ver Peralta. 
desarrolladas durante el gobierno de facto de Juan Carlos Onganía (19661970) mantuvieron como foco de especial preocupación a los homosexuales y otros sujetos sexualmente transgresores. El mismo año de aparición de la novela de Mujica Lainez, Carlos A. Da Gris denunciaba en El homosexual en la Argentina las persecuciones policiales y la estigmatización social de que eran víctimas los hombres que se relacionaban con otros hombres: "Muchos se suicidan al verse descubiertos porque temen que su mancha caiga sobre los familiares y prefieren ese fin antes que lo otro. [...]. No es que sientan vergüenza o que la tengan o dejen de tenerla. Repito: TEMEN a las brutales represalias de la policía" (20). Aunque a finales de la década se formaría "Nuestro Mundo", asociación pionera de lucha por los derechos de las minorías y germen del posterior Frente de Liberación Homosexual, en términos generales los años sesenta no supusieron un cambio sustancial en lo que respecta a las sexualidades periféricas.

En el Medioevo imaginado por Mujica Lainez en esos años, muchos personajes desbordan los patrones sexo-genéricos estrictos, pero la disidencia homoerótica tiene un límite; no tanto, a mi juicio, por un afán de verosimilitud, como por una (auto)exigencia discursiva que impedía mostrar el amor entre varones bajo una luz positiva. Téngase en cuenta, en este sentido, que tanto el relato "La narración de la historia" (1959) de Carlos Correas, como la novela Asfalto (1964) de Renato Pellegrini fueron procesadas por obscenidad y que lo mismo sucedería pocos años después con otra novela, La boca de la ballena (1973) de Héctor Lastra: en estos textos, el solo hecho de que el deseo homosexual no se concibiera como pecado, enfermedad o delito dinamitó los parámetros morales de la época. No obstante, la evidencia más poderosa de que El unicornio no solo está hablando de la Francia medieval sino también de la Argentina contemporánea se encuentra en la novela posterior Sergio, ambientada en la década de 1970 y una de las pocas del autor de temática homoerótica explícita. Los numerosos y significativos paralelos entre el protagonista de esta novela y el de El unicornio, Aiol de Lusignan, así como el desenlace similar -por imposible- de los amores masculinos, manifiestan una misma encrucijada temático-ideológica, resuelta en un caso bajo la forma de una novela histórica-maravillosa y, en el otro, como fábula de iniciación con algunos rasgos de picaresca ${ }^{20}$.

20 Tanto Aiol como Sergio encarnan bellos efebos que despiertan el interés erótico de hombres y mujeres. La diferencia radica en que Sergio va mucho más lejos que El unicornio en la exploración de la identidad y la experiencia homoeróticas del protagonista. Laera sugiere 
En El unicornio Mujica Lainez recuperó e hizo propia la leyenda del hada Melusina, que de acuerdo con Carlos Alvar "es una de las más atractivas de las que surgieron en la Edad Media: es el relato de la vida de un hada, que se convierte en mujer por amor y que después es condenada a vivir como serpiente con alas al ser víctima de una promesa incumplida" (10). Aunque los orígenes del mito se remonten a la literatura oral, la principal fuente escrita es Melusina o la noble historia de Lusignan, narración compuesta por Jean D'Arras a finales del siglo XIV. Sobre la base de este y de otros materiales, Mujica Lainez urdió una trama claramente dividida en dos partes (Fernández Ariza 408): la primera (Mujica Lainez 11-33) constituye, según la narradora -la misma Melusina- un "cuento de hadas" (33); se trata, en efecto, de una síntesis de la leyenda, fiel a sus principales peripecias: la unión del hada con un mortal, Raimondín; la infracción, por parte de este, de la prohibición de ver a Melusina los días sábados (en los que ella pierde su apariencia humana); y las nefastas consecuencias de esta transgresión: la metamorfosis definitiva en mujer-serpiente alada y la condena a la inmortalidad. La segunda parte (33-375) suma otro mito, el del unicornio (Nogueras 478), y su principal vector dramático es la vida de un descendiente remoto de Melusina, Aiol de Lusignan, de quien el hada se enamora y a quien (per)sigue en un extenso viaje que finaliza en Tierra Santa, tras numerosos e intrincados episodios que entablan un diálogo intertextual con la historia, la literatura y la cultura medievales, según han analizado extensamente otros $\operatorname{críticos}^{21}$. Un acontecimiento determinante de esta segunda parte tiene lugar cuando Melusina, para poder acercarse a su amado, solicita a su madre, el hada Presina, que le dé un cuerpo humano. Presina accede pero, no sin cierta malicia, le provee un bello cuerpo de varón, circunstancia que imposibilita el encuentro de los amantes.

La disidencia homoerótica se manifiesta de modos muy diversos en la novela. Se ha señalado la singularidad de la voz narradora, Melusina, que debido a su condición inmortal puede narrar sucesos del pasado con una perspectiva moderna; además, el hecho de ser, durante la mayor parte de la

que quizás "la posibilidad de una iniciación homosexual liberada de todo trauma y vinculada únicamente con el goce haya sido posible, en Mujica Lainez, porque justo antes, en uno de los primeros capítulos de la novela El laberinto, había un relato bien frívolo de la belleza y el deseo" (34).

21 Véanse, por ejemplo, los trabajos de Frances Vidal (143-155), Cerrada Carretero (351- 402) e Iurilli (s/d). 
novela, un hada (y como tal, invisible), la dota de una privilegiada posición de omnisciencia ${ }^{22}$. Menos atención ha concitado otra circunstancia, por lo demás evidente: se trata de una voz narrativa femenina. Comentando otra novela de Mujica Lainez, La casa (1953), Abelardo Castillo hizo una interesante observación: "[el escritor escogió] el femenino para narrar: 'Soy vieja, revieja'. Así empieza La casa. Se sabe que Mujica Lainez era homosexual [...] De modo que el uso del femenino es una especie de chiste. No podía ignorar el malestar y el pequeño sobresalto que causan esas dos palabras" (Castillo en Margulis 144). Mucho más subversiva resulta, a mi juicio, la narradora de El unicornio, sobre todo si se tiene en cuenta que al margen de los numerosos episodios de carácter histórico que relata, uno de los ejes principales de su evocación autobiográfica es la fervorosa pasión que despertó en ella Aiol de Lusignan, joven de extraordinaria belleza que responde al prototipo del efebo ${ }^{23}$. La elección de este punto de vista habilita entonces un discurso erótico-amoroso que no hubiera sido posible (ni aconsejable) articular desde una posición enunciativa masculina. Además, a través de Melusina, Mujica Lainez puede establecer una mirada de deseo hacia el cuerpo masculino, según ilustra, entre muchos otros pasajes, el siguiente: “Así desvestido, comprobé, pese a mi inexperiencia y a que se refugió para la tarea detrás de un arbusto, el minucioso esplendor de su hermosura” (21). Debe tenerse en cuenta también que, de acuerdo con algunas interpretaciones biográficas basadas en testimonios del propio Mujica Lainez, los protagonistas y narradores de Bomarzo y El unicornio poseerían rasgos del autor "real”. Sobre la identificación con Melusina, concretamente, el escritor sostuvo

22 Destaca, en el inicio del capítulo III, la capacidad que adquiere Melusina de "penetrar" en el pensamiento de Aiol: "Los pensamientos ocultos y la memoria de Aiol fueron míos, de aquella noche de verano en más" (103). Este acceso privilegiado a la interioridad del muchacho contrasta con la posibilidad de poseerlo físicamente, que constituye el mayor deseo de Melusina.

23 En diversas ocasiones, Melusina lamenta la imposibilidad de una unión física con Aiol; cuando es hada, por su condición sobrenatural: “¡Estábamos tan cerca, tan cerca! Mis pezones rozaban su pecho moreno, no bien se movía, y si Aiol alargaba un brazo encontraba en su camino a mi cintura o a mis cabellos o a mis alas o mis escamas" (132); cuando es caballero, por su condición masculina: “¿Merecía, después de haber sido un hada robada de sus poderes, convertirme en un mozuelo, cuando lo que ansiaba era conquistar un cuerpo de mujer, bello y joven, para con él lograr a mi amado?" (206). Tal vez, a este respecto, Melusina se esté revelando como excesivamente moderna, pues, de acuerdo con Mérida Jiménez (2000: 71), la mentalidad dominante medieval "no aceptaba la posibilidad de la búsqueda del placer a través de la sexualidad”. 
que "cambiar de sexo, permite mirar todo desde ángulos distintos; como consecuencia, puede ser que psicológicamente se parezca a mí" (Mujica Lainez en Cerrada Carretero 95) ${ }^{24}$.

El efecto de extrañamiento que ejerce la peculiar narradora de la novela aumenta cuando en el capítulo V, titulado "Un cuerpo para Melusina" (181215), el hada se transforma en el caballero Melusin de Pleurs. Como advierte Nogueras, la "triple condición de 'hada, mujer y hombre' de la memorialista, le permite a Mujica divagar sobre la ambigüedad y la labilidad, de las identidades" (481). En efecto, los disfraces son un motivo recurrente en El unicornio, y varias veces asistimos a la revelación de la identidad "verdadera" de un personaje que se había ocultado en el nombre y la apariencia de otro/a ${ }^{25}$. No obstante, ninguna transformación resulta tan radical -y tan trágica- como la de Melusina, pues implica la imposibilidad irremediable del vínculo que el hada desearía establecer con el bello y esquivo Aiol:

Y más que nada me costaba acostumbrarme a la idea de que yo, Melusina de Lusignan, era un hombre. Claro que no me acostumbré. No me acostumbré nunca. No contaba con la menor vocación para la masculinidad. Seguía gimoteando por lo bajo, tocándome toda, inaugurando la incomparable excitación de ser mujer y hombre al mismo tiempo, y hasta preguntándome si no hubiera sido posible, de no amar a Aiol, que me amara a mí misma, que yo misma me amara a mí mismo, pero la coyuntura de ese narcisismo bifurcado, de esa sensual autarquía, que sin dudas hubiera encerrado ventajas de práctica comodidad muy notables, no se presentaba como una solución provechosa para mi estado complejo, pues continuaba amando a Aiol con pasión igual, a pesar de la incongruencia de mi envoltura (206).

$24 \quad$ También Cruz (Cit. en Melo 175) considera que El unicornio es una de las novelas “donde 'Manucho' se refleja con mayor autenticidad y donde pueden encontrarse rasgos profundamente autobiográficos". Otro dato sobre las posibles conexiones entre la novela y un sustrato biográfico se encuentra en la biografía de Mujica Lainez que escribió su amigo Oscar Hermes Villordo. Según testimonio de José Luis Lanuza, la escena en que Aiol se encuentra desnudo en una tina de baño, acompañado por el hada Melusina, se inspiraría en una escena "real" de la vida del escritor, ocurrida en un hotel de Necochea. Lanuza visitó a "Manucho" en dicho hotel y lo encontró escribiendo en la cama, mientras que en el baño, envuelto en una nube de vapor, se daba un baño el joven Carlos Bruchmann (Villordo 233).

25 Es el caso, por ejemplo, de Azelaís, hermana de Aiol. 
La metamorfosis de Melusina implica otra forma de disidencia, ya no homoerótica, sino, en sentido amplio, corporal. Probablemente sin proponérselo, Mujica Lainez acaba ofreciendo una interesante reflexión -en clave fantástica-sobre el fenómeno de la transexualidad, que en aquellos años comenzaba a ser una realidad posible gracias a los avances en la cirugía de reasignación sexual ${ }^{26}$. La "incongruencia" entre el cuerpo de Melusina y su autopercepción genérica correspondería a lo que en campo médico-psiquiátrico se denomina "disforia de género" ${ }^{27}$. En la lógica de la novela, esa incongruencia no constituye, sin embargo, un rasgo patológico del personaje, sino una condición "fantástica" que subraya su carácter extraordinario. Melusina, como el conde jorobado de Bomarzo, es un ser diferente, "fuera de la norma”, pero cuya diferencia no redunda en condena o marginalidad; sino que, por el contrario, lo eleva por encima de los demás (superioridad subrayada por el hecho de que, al ser un hada, Melusina puede volar y observar a los humanos desde lugares privilegiados). La supremacía de personajes “raros” y sexualmente ambiguos podría valorarse como una reivindicación velada, en la línea de la estrategia discursiva inversa en la que, según Dollimore, los sujetos disidentes invierten los términos y se declaran "superiores" a quienes, a su vez, los consideran "inferiores" (226).

También resulta productivo analizar la "transexualidad" de Melusina a partir de las reflexiones de Judith Butler sobre el género. De acuerdo con esta autora, la coherencia interna de cualquier género, femenino o masculino, requiere una heterosexualidad estable que sirva de oposición:

Esa heterosexualidad institucional exige y crea la univocidad de cada uno de los términos de género que determinan el límite de las posibilidades de los géneros dentro de un sistema de género binario y opuesto. Esta concepción del género no sólo presupone una relación causal entre sexo, género y deseo: también señala que el deseo refleja o expresa al género y que el género refleja o expresa al deseo (80).

$26 \quad$ Uno de los primeros casos mundialmente famosos fue el de la norteamericana Christine Jorgensen (1926-1989), quien se sometió a la cirugía de reasignación de sexo (de varón a mujer) en 1951. También alcanzó celebridad la transexual francesa Coccinelle (19312006), vedette y cantante que visitó varias veces Argentina durante los años sesenta e incluso filmó en el país la película Los viciosos (1962) de Enrique Carreras, con Jorge Salcedo y Graciela Borges.

$27 \quad$ Ekins (Cit. en Soley Beltrán 62) define la disforia de género como "el sentido de malestar o incomodidad acerca de la identidad de uno como hombre o como mujer que se siente en oposición al sexo físico de uno”. 
El conflicto que se plantea a Melusina una vez convertida en caballero radica en que se quiebra la unidad de la que habla Butler: el personaje no puede desear a otro hombre ahora que su sexo y género son masculinos. Mujica Lainez, sin cuestionar el binarismo hombre/mujer (que aparece como natural), logra poner en evidencia su carácter opresivo, pues Melusina debe renunciar a Aiol, incapaz de cumplir el requisito de heterosexualidad que rige las relaciones entre hombres y mujeres. Esta "desgracia” no se narra, sin embargo, en un tono solemne o trágico. La nota predominante, para Schanzer, es la ironía, a través de la cual se relativiza la gravedad de los eventos $(89)^{28}$. El humor permite, además, burlarse de las fronteras estrictas de los géneros, de modo que mientras Melusina es "humano", la voz narradora proyecta textualmente la androginia del personaje, dando lugar a situaciones equívocas:

Al salir, vacilante, me apoyé en el brazo de Aiol.

-¿Qué te sucede?

-Estoy cansada. Jamás estuve tan cansada.

- ¿Cansada?

-Cansado. Ya no sé qué digo, Aiol (267).

Como bien apunta Adrián Melo, Melusina encarna en esta sección de la novela la metáfora del "homosexual" como mujer encerrada en el cuerpo de un hombre (174), difundida durante la segunda mitad del siglo XIX por el sexólogo alemán Karl Heinrich Ulrichs (Llamas 355-356). El hada debe guardar en secreto los sentimientos que alberga hacia Aiol: permanece, en este sentido, en una especie de $\operatorname{armario}^{29}$ y su interés erótico-amoroso por el joven pierde incluso entidad narrativa, ya que la acción se ocupa de manera exclusiva de las guerras y luchas de poder en Jerusalén. En el último capítulo, sin embargo, Melusina resuelve, en el umbral de una batalla decisiva, revelar al muchacho sus verdaderos sentimientos: “-Aiol -le dije-, es probable que

28 Frances Vidal (1986: 139), de modo similar, afirma: "En El unicornio se inicia un tono burlesco, zumbón, muy propenso a la risa, y que marca notablemente la obra posterior del autor".

29 Como queda de manifiesto, por ejemplo, en el siguiente pasaje: "Hoy pienso que de las variadísimas formas del amor, la que me correspondió investir junto a Aiol de Lusignan, insatisfecha, inmolada, abnegada, imposible, sin más recompensa que la contemplación del amado, quien debía ignorar hasta la existencia de la pasión que a su lado, en su propio lecho, ardía, es la predestinada, en su muda entrega espiritual, en su aniquilamiento, a rozar los substratos más profundos de un nexo que está condicionado por la capacidad de darse" (311). 
nos siegue la Muerte. Antes de que eso acontezca debo sacarme del pecho la espina de una confesión. Yo te amo; te amé cuando aún no me conocías" (355). La reacción inmediata de Aiol es de pánico, pero su réplica se ve postergada por los movimientos de las tropas, y tampoco llegamos a conocerla más tarde, ya que Melusin de Pleurs muere en el enfrentamiento con los infieles $\mathrm{y}$, de ese modo, Melusina torna a ser un hada. El único testimonio del efebo sobre sus relaciones con Melusin aparece en un diálogo posterior, en el que los guerreros evocan al caído:

-Ha sido -sentenció Reinaldo- un nobilísimo caballero.

-No conocí amigo mejor -replicó el joven.

-Yo solía pensar en vosotros como unos arquetipos de la pareja guerrera -añadió el señor, nutrido de lecturas clásicas [...]-; un remedo admirable de Aquiles y Patroclo, de Orestes y Pílades, de Teseo y Piritoo.

-Nos amábamos -exclamó Aiol- como hermanos. Ahora no tengo a nadie (362).

La relación entre Aiol y el caballero/hada se integra, en este pasaje, a una larga tradición occidental de célebres parejas masculinas cuyo vínculo amistoso también podría contener matices eróticos y sentimentales. Halperin ha señalado la "amistad” o "amor masculino" como una de las cuatro categorías que preceden al concepto moderno de homosexualidad $(117-121)^{30}$. Se trata de un patrón prestigioso que permite a Mujica Lainez "elevar” el carácter de la relación que une a los protagonistas. Por otra parte, en sintonía con el sesgo irónico que caracteriza la novela, la dudosa masculinidad de uno de los miembros de la pareja de guerreros introduce una nota de ambigüedad y pone en entredicho la pretendida legibilidad del sujeto "homosexual" 31.

30 Las otras tres son "afeminamiento”, "pederastia” o "sodomía activa” y “pasividad” o "inversión” (Halperin 109).

31 Edelman sostiene que la ideología heterosexista ha insistido, a lo largo del siglo $\mathrm{XX}$, en la necesidad de "leer" el cuerpo como un significante de la orientación sexual: "la heterosexualidad ha podido, por consiguiente, ser capaz de reforzar el estatus de su propia autoridad como 'natural' (es decir, no marcada, auténtica y no-representacional) definiendo el cuerpo heterosexual contra la "amenaza" de una homosexualidad "no natural" -una amenaza mucho más efectivamente movilizada por el hecho de crear preocupación acerca de la capacidad inquietante (y estratégicamente manipulable), de la homosexualidad de "pasar por", de permanecer invisible [...]" (4). 
Otras huellas de disidencia homoerótica aparecen de la mano de personajes secundarios explícitamente representados como hombres que aman a otros hombres. El retrato de Aymé de Castel-Rousillon, dueño del castillo al que llegan Aiol y otros personajes en el capítulo IV, se inicia con esta descripción: “era un hombre curioso y, como pronto se apreciará, más curioso de lo que a primera vista parecía” (127). Conforme avanza el capítulo, la singularidad de Aymé se va desvelando y se descubre que a pesar de estar casado con Seramunda, siente una profunda atracción por Aiol. De hecho, los esposos se disputan al muchacho, pero solo Seramunda consigue conquistarlo, ya que su marido "no se atrevía a dar el paso definitivo, a forzar la situación, por miedo a un escándalo que lo convertiría en el hazmerreír de los otros castillos" (156). Resulta sospechosamente "moderna" esta descripción de Aymé como un sujeto armarizado $^{32}$, que teme las posibles consecuencias negativas de la revelación pública de sus preferencias eróticas. Como evidenció el análisis brillante de Eve Kosofsky Sedgwick, la definición de la homo/heterosexualidad -y la crisis epistemológica que trajo aparejada- constituye un fenómeno característico de finales del siglo XIX, que se profundizó en el XX. Una vez más, da la impresión de que Mujica Lainez habla menos de la Edad Media que del momento de redacción de la novela. La idea de un “escándalo” podía resultar problemática para un homosexual de los años sesenta, especialmente si era miembro de las clases medias y altas ${ }^{33}$. El mismo Mujica Lainez, por ejemplo, escribió el prólogo para la novela explícitamente homosexual Asfalto (1964) de Renato Pellegrini, pero se negó a firmarlo: "con este libro te meterán preso y yo no quiero verme metido en ese lío" (Pellegrini en Bazán 26). En línea con los presupuestos de la "homofilia" 34 , muchos homosexuales de la época aspiraban a la integración y la respetabilidad a cambio de no llamar la atención. Dadas las consecuencias impredecibles de su desvelamiento público,

$32 \quad$ El término se aplica, según Rodríguez, al sujeto "que está dentro (o sea, que no ha salido) del armario" (28). A su vez, "Armario", según el mismo investigador, designa la "clandestinidad en la que vive alguien que se resiste a revelar su condición de homosexual por considerarla vergonzante" (27).

33 La película inglesa Victim (1961) de Basil Dearden, protagonizada por Dirk Bogarde, abordaba precisamente el tema del chantaje contra homosexuales de buena posición económica. Da Gris, en el libro ya citado, analiza extensamente este fenómeno en el contexto argentino.

$34 \quad$ De acuerdo con Llamas, "los discursos homófilos, típicos de la militancia semiclandestina en Europa y Norteamérica durante las décadas de los cincuenta y los sesenta, postulan la integración y reclaman la tolerancia alejándose de cualquier excepcionalidad y renunciando (al menos formalmente) a cualquier especificidad" (361). 
era necesario que la homosexualidad conservara su estatus de "secreto" (o, en algunos casos, de "secreto a voces"). Se trata, entonces, de una problemática mucho más contemporánea que medieval pues, durante la época que la novela reconstruye los comportamientos sexuales no "definían" la identidad sexual de las personas: "la sexualidad es, de hecho, como sostuvo Foucault, una producción distintivamente moderna" (Halperin 29).

El episodio de Aymé tiene un desenlace desafortunado, pero sería problemático deducir que un imperativo trágico se cierne sobre el personaje "homosexual”, pues también Seramunda y Guillermo de Cabestah (secretamente enamorado de ella) "acaban mal". En general, puede afirmarse que las prácticas sexuales transgresivas -incesto, adulterio, homoerotismo- reciben una valoración moral negativa, que puede ir -o no- acompañada de una sanción. En el caso de Aiol y Azelaís, los hermanos incestuosos, ellos mismos se imponen un castigo por la infracción cometida y buscan afanosamente la purificación, física y espiritual.

Otro personaje secundario a quien se le atribuye el "pecado nefando" es el rey Onfroi IV, anfitrión temporal de Aiol y sus acompañantes. En un breve episodio del capítulo VII, la narradora observa:

Mujeres muy pocas vi en Torón. Mercator, al tanto de todo, nos recordó [...] los comentarios que corrían en la corte acerca del joven Onfroi IV. Se lo tenía allí por un muchacho raro, solitario, misógino, tímido, buen soldado [...], pero representante avanzado de los potrillos reñidos con las normas tradicionales de la moral. Educado entre orientales de conversión dudosa, [...], extraordinariamente hermoso, chocaba por su narcisismo provocante y por el hecho de que prefería rodearse de pajes y esclavos agraciados [...] (299).

La descripción de Melusina aglutina diversas imágenes estereotípicas del "homosexual" (raro, misógino, narcisista) e insiste en su oposición a la moral tradicional. Sin embargo, en este caso, el contexto de la corte parece autorizar la conducta errática del disidente. A la manera de un Luis II de Baviera medieval ${ }^{35}$, el excéntrico Onfroi ha creado un espacio en sintonía con

35 Luis de Wittelsbach (1845-1886), príncipe bávaro de la Casa de Wittelsbach, fue rey de Baviera entre 1864 y 1886. Por su carácter excéntrico, atrajo la atención de varios creadores, entre ellos el novelista Klaus Mann y los cineastas Luchino Visconti y Hans-Jürgen Syberberg. 
su deseo: "mullidos tapices", "braseros desbordantes de flores aromáticas" y un grupo de khawals -prisioneros egipcios musulmanes "que desde niños se vestían como mujeres" (301)- son algunas de los piezas que componen el aposento del monarca. Podría trasladarse a Onfroi la observación que Aaron Betsky, en su estudio de los espacios queer, dedica a Luis II: "los palacios que creó fueron artefactos auto-contenidos a través de los cuales él podía definirse a sí mismo" (74). El clima decadente en el que vive, sumado a su deliberada ambigüedad, está a punto de escandalizar a la narradora, que sin embargo se ve obligada a reflexionar en estos términos: "en verdad, ¿podía yo vituperarlo a Onfroi? Lo confuso, lo equívoco de mis propios sentimientos, derivados de mi simultánea condición que participaba de un sexo y del otro, me vedaba cualquier censura" (302). Melusina manifiesta una actitud ambivalente -justificada en su doble condición de hada y de caballero- de tal modo que las licencias morales que se toman algunos personajes reciben una justificación, como en este caso, pero al mismo tiempo se deja en claro su inconveniencia. Mujica Lainez parece tener en cuenta las posibles reacciones de lectores más y menos receptivos a la representación de sexualidades no normativas. A fin de cuentas, uno de los ejes vertebradores de la novela, en el plano ideológico-temático, es la dualidad entre el Bien y el Mal, lo Puro y lo Impuro ${ }^{36}$, como se pone de manifiesto a través del símbolo del unicornio, según analizó Sandro Abate (30-31).

El tercer personaje homoerótico de El unicornio es el duende Oberón, quien en reiteradas ocasiones pone a disposición de Melusina sus poderes mágicos, especialmente cuando el hada, convertida en caballero, pierde por completo los privilegios feéricos. En el diálogo que ambos personajes mantienen en el capítulo VI, Oberón cuenta su historia y se manifiesta, así, la similitud de su desventura amorosa y la de Melusina:

¡Ay, Melusina! Tu dilema es, hasta cierto punto, semejante al mío. Ambos nos hemos enamorado de un imposible. Pero, si bien se

36 Según Fernández Ariza, es el personaje de Aiol de Lusignan el que mejor encarna esta dualidad, pues se debate "entre la llamada del Espíritu y de la Carne, 'entregándose sucesivamente a esas alianzas opuestas'; embarcado en la empresa mística -la búsqueda de la Santa Lanza- y 'hostigando con su voracidad a las doncellas del castillo de Beaufort'. Todo refleja una personalidad contradictoria simbólicamente sintetizada en las enigmáticas alusiones a sus atributos: la extrañeza de poseer 'dos ojos distintos, uno de grifo y otro de dragón, 'un ojo azul y un ojo de oro', un ojo para Dios y un ojo para el Diablo” (420). 
mira, todo gran amor es imposible y en eso finca su grandeza. Yo, que soy un hombre-hada, tuve la desgracia, o la suerte (porque mi desgracia me ha hecho desconcertantemente feliz), de enamorarme de un hombre valiente y hermoso; tú, que eres una mujer-hada, estorbada por un cuerpo de hombre, te has enamorado de otro hombre, hermoso y valiente también. Ninguno de ellos, ni Huon de Burdeos ni Aiol de Lusignan, ha sido o será capaz de amarnos. [...] Estamos condenados a la soledad, a arder como lámparas solas. Es lógico que padezcamos y que a menudo nos rebelemos contra la injusticia cruel de una situación desigual que no hemos seleccionado, y es lógico, asimismo, que a veces nos falten las fuerzas para seguir adelante con tal desproporcionada y disparatada tortura, mas nuestro acicate se cifra, creo yo, precisamente en la iniquidad tirana que nos aflige y nos reduce a la amargura de víctimas inocentes. Todo amor verdadero es puro. Tu amor y el mío lo son y eso basta para redimirlos y exaltarlos, pese a cualquier torpe crítica e hipócrita convención. Tendrás que resignarte, Melusina, a dar calor y luz. Y a esperar (260).

El discurso de Oberón articula nítidamente varios presupuestos sobre los amores homoeróticos, algunos de claro signo homófilo, como la insistencia en la "pureza” (que los redimiría a ojos de la sociedad bienpensante). La imposibilidad que marca las relaciones de estos personajes fantásticos podría leerse, en términos actuales, como la que muchas veces experimentaban los homosexuales afeminados ("hadas") en sus vínculos con varones heterosexuales, atractivos y masculinos ("hermosos” y “valientes”): las novelas de Oscar Hermes Villordo -amigo y biógrafo de Mujica Lainez- abundan en ejemplos de romances fallidos entre "locas" y "chongos" ${ }^{37}$. Las referencias a la soledad y al sufrimiento entroncan, por su parte, con un imaginario negativo sobre el "homosexual": vale la pena tener en cuenta que la novela se publicó en 1965, años antes de que empezaran, en Argentina, las luchas por la reivindicación de las minorías sexuales. Para Ernesto Meccia (2011 103), de hecho, los homosexuales de los años cuarenta, cincuenta y sesenta habrían formado parte de una "una sola generación trágicamente dilatada por décadas a causa del silencio". Las injusticias padecidas por una "situación desigual” constituyen, por lo demás, un tópico extensamente desarrollado por Da Gris en el estudio publicado el mismo año que El unicornio: "si hay

37 Véanse, por ejemplo, La brasa en la mano (1983) y La otra mejilla (1986), ambientadas en los años cincuenta y en la última dictadura militar (1976-1983), respectivamente. 
algo que la ley debe corregir, es la situación de los homosexuales" (145). El diálogo entre Melusina y Oberón, en suma, parecería tratar, oblicuamente, una serie de cuestiones relativas a las relaciones entre varones que tenían plena vigencia en el momento en que Mujica Lainez escribía, y que el autor no habría podido expresar sin acudir al subterfugio del emplazamiento medieval.

Otro fragmento revelador acerca de la "homosexualidad" aparece en el episodio sobre Onfroi IV que comentamos anteriormente:

No se asombre el lector y no piense que es menester pasar de los antiguos romanos al redescubrimiento italiano del paganismo, para encontrar tipos como el cuarto Onfroi de Torón. También los hubo en la Edad Media y, con matices distintos, lo reafirma lo que apunté con referencia a Aymé de Castel-Rousillon y su desventura. El hombre -me lo enseña mi pericia de personaje que persiste a través del tiempo- es siempre el mismo, en todas sus épocas. [...] no varía. Onfroi IV hubiera podido ser un contemporáneo de quien me lee y un contemporáneo de Alcibíades, de Adriano o de Pier Francisco Orsini, duque de Bomarzo, como era un contemporáneo del sire Aiol (300).

Melusina rivalizaría con quienes afirman, siguiendo la senda abierta por Michel Foucault, que la "homosexualidad" es una construcción histórica y cultural, pues estas líneas la revelan como una encendida defensora de la posición esencialista ${ }^{38}$. Aunque la narradora utilice el sustantivo común "hombre”, resulta claro, por el resto de referencias, que está aludiendo a personajes de sexualidad heterodoxa, y que el objetivo del pasaje consiste en establecer una pequeña genealogía que remite, además, a la novela previa de Mujica Lainez, Bomarzo. No sería el "hombre” el que es igual en todas las épocas, sino, en particular, esos "tipos” que no cumplen con las imposiciones de la moral ordinaria ${ }^{39}$. La inclusión, en esa sugerente red genealógica, del posible lector "contemporáneo”, constituye un claro gesto de complicidad que confirma la hipótesis de Brizuela: Mujica Lainez no solo escribió literatura de temática homoerótica, sino que a través de sus obras, transmitió capacidades y competencias a un público lector específico (83). En todas sus obras, tanto

38 Sobre el debate esencialismo vs. construccionismo, véase el balance que llevan a cabo Cleminson y Vázquez García (5-10).

39 Curiosamente, este fragmento es citado por Schanzer (89) y Nogueras (483) para señalar que el tema que interesaba a Mujica Lainez en esta y en otras novelas "históricas” era la condición humana en un sentido amplio. 
las “argentinas" como las “europeas” aparecen, en efecto, personajes y situaciones que desbordan los parámetros heteronormativos y que descubren cuerpos, deseos y afectos ubicados en los márgenes de la ley. Los lectores capaces de acceder a esos contenidos y significados habrán establecido una relación muy particular con esos textos, diferente a la de otros sectores del público; en todo caso, lo verdaderamente singular radica en el hecho de que El unicornio pudiera convocar por igual a unos y a otros, y quedar a salvo de los acechos de la censura.

He señalado, hasta aquí, huellas de disidencia homoerótica que conciernen a la voz narradora, a la organización argumental y al nivel temático. Sería interesante considerar también la posibilidad de una disidencia formal, estrictamente lingüística. En un ensayo, Sylvia Molloy caracterizó a Mujica Lainez y al poeta mexicano Salvador Novo como "esos Liberaces de la cultura latinoamericana" $(819)^{40}$. El estilo del autor podría asimilarse, ciertamente, al del pianista norteamericano, pues abunda en excesos y brillos retóricos que han sido objeto, muchas veces, de dura reprobación por parte de los críticos. Isaías Lerner, por ejemplo, en su reseña de El unicornio, cuestionó "la enumeración indiscriminada de objetos, piedras, telas, afeites o sonidos, en verborrágico acoplamiento" como así también la abundancia de descripciones "que retardan, sin beneficio aparente, el desarrollo y la acción de la novela" (166). Otros estudiosos han destacado la centralidad de la Belleza, como tema y como forma, en la obra del escritor (Laera 2005). Así, Luis Antonio de Villena, introductor de la obra de Mujica Lainez en España, afirmó: "sobre todo, una pasión de arte. El afán de la ambivalencia y de la máscara, de la sugerencia, al fin, que enriquece más el texto y su tono" (32). Desde esta perspectiva, la disidencia homoerótica involucraría también el plano del lenguaje; existiría, en definitiva, una conexión entre deseos y afectos "fuera de la norma" y la maquinaria verbal que los expresa. Mujica Lainez revelaría, en obras como El unicornio, "una sensibilidad camp de avanzada” (Zangrandi s/d), muy diferente a la de autores más jóvenes como Manuel Puig o Ernesto Schoo, pero no menos significativa por su contribución al desmantelamiento de la "solemnidad” heterosexual de buena parte de la literatura argentina coetánea.

40 Wladziu Valentino Liberace (1919-1987), conocido como Liberace, fue un popular pianista y showman norteamericano de ascendencia polaca e italiana, famoso por la espectacularidad -y el marcado toque kitsch- de sus presentaciones. 
En suma, puede afirmarse que Mujica Lainez logró articular en El unicornio una trama con importantes componentes homoeróticos, en un marco histórico y sociocultural adverso, en general, a las manifestaciones explícitas de deseo y de amor entre varones. El escritor afirmó en una entrevista que su objetivo con esta novela fue presentar "una visión personalísima de la Edad Media" bajo la forma de "una sucesión de escenas (tableaux) de constante ironía" (Schanzer 86). Los esfuerzos de la crítica por establecer los referentes auténticos parecen ignorar la dimensión satírica a partir de la cual fue concebida. La incorporación del homoerotismo como elemento crucial corroboraría la intención de crear un Medioevo "personalísimo", a través de cuyas figuras y motivos el autor aludía a la más candente -e incómoda- actualidad.

\section{FUENTE}

Mujica Lainez, Manuel. El unicornio. 1965. Barcelona: Seix Barral, 2005. Sergio. 1976. Buenos Aires: Sudamericana, 1977. El viaje de los siete demonios. 1977. Buenos Aires: Planeta, 1992.

\section{BIBLIOGRAFÍA}

Abate, Sandro. "Psicología y simbolismo en El unicornio de Mujica Lainez". Actas del XIV Congreso de la Asociación Argentina de Hispanistas, IV, Literatura Hispanoamericana. Eds. Isaías Lerner, Robet Nival y Alejandro Alonso. Newark, Delaware: Juan de la Cuesta, 2004. 27-33.

Alvar, Carlos. "Prólogo”, Melusina o la noble historia de Lusignan de Jean D’Arras. Trad. Carlos Alvar. Madrid: Alianza, 1999. 7-24.

Bazán, Osvaldo. "El escritor que se adelantó medio siglo”. Crítica de la Argentina (2008): 26-27.

Ben, Pablo y Omar Acha. “Amorales, patoteros, chongos y pitucos. La homosexualidad masculina durante el primero peronismo (1943-1955)". Trabajos y Comunicaciones 3031 (2004-2005): 217-260.

Ben, Pablo. Male Sexuality, the Popular Classes and the State: Buenos Aires, 1880-1955. Tesis doctoral. University of Chicago, 2009.

Betsky, Aaron. Queer Space. Architecture and Same-Sex Desire, New York: William Morrow, 1997.

Brizuela, Leopoldo. "El manifiesto secreto: ambigüedad y política en la obra de Mujica Lainez". Desde aceras opuestas. Literatura/Cultura gay y lesbiana en Latinoamérica. Ed. Dieter Ingenschay. Madrid-Frankfurt: Iberoamericana-Vervuert, 2006. 75-88. 
Butler, Judith. El género en disputa. El feminismo y la subversión de la identidad. 1991. Trad. Patricia Soley Beltrán. Barcelona: Paidós, 2007.

Caballero, María. Novela histórica y posmodernidad en Manuel Mujica Lainez. Sevilla: Secretariado de Publicaciones, 2000.

Cerrada Carretero, Antonio. La narrativa de Manuel Mujica Lainez. Tomo I. Madrid: Universidad Complutense de Madrid, 1990.

Cleminson, Richard y Francisco Vázquez García. Los invisibles. Una historia de la homosexualidad en España, 1850-1940. Granada: Comares, 2011.

Cosse, Isabella. Pareja, sexualidad y familia en los años sesenta. Una revolución discreta en Buenos Aires. Buenos Aires: Paidós, 2010.

Da Gris, Carlos A. El homosexual en la Argentina. Buenos Aires: Continental Service, 1965.

Dollimore, Jonathan. Sexual Dissidence. Augustine to Wilde, Freud to Foucault. Oxford: Clarendon, 1991.

Duggan, Lisa y Nan D. Hunter. Sex Wars. Sexual Dissent and Political Culture. 1995. New York: Routledge, 2006.

Edelman, Lee. Homographesis: Essays in Gay Literary and Cultural Studies. New York, Routledge, 1994.

Fernández Ariza, Guadalupe. "El unicornio de Manuel Mujica Lainez: tradición literaria y constantes genéricas”. Revista Iberoamericana LVIII. 159 (1991): 407-421.

“Los disfraces del hada Melusina en El unicornio de Manuel Mujica Lainez”. Escribir el cuerpo: 19 asedios desde la literatura hispanoamericana. Eds. Carmen de Mora Valcárcel y Alfonso García Morales. Sevilla: Universidad de Sevilla, 2003. 77-88.

Frances Vidal, Sorkunde. La narrativa de Mujica Lainez. Bilbao: Universidad del País Vasco, 1986.

Gorza, Anabella. “'Médicos civilizados, sexualidades perversas': una mirada médica de las identidades de género no convencionales durante el primer peronismo (1946-1955)". Trabajos y Comunicaciones 36 (2010): 187-202.

Guy, Donna. Sex and Danger. Prostitution, Family and Nation in Argentina, Lincoln-London: University of Nebraska, 1991.

Halperin, David. How to Do the History of Homosexuality. Chicago-London: The University of Chicago, 2002.

Iurilli, Aurelia. “Claves y glosas para leer El unicornio”. Culture 15 (2001). http://goo.gl/BLU3N. Jáuregui, Carlos. La homosexualidad en la Argentina. Buenos Aires: Tarso, 1987.

Laera, Alejandra. "Prólogo". Los dominios de la belleza. Antología de relatos y crónicas de Manuel Mujica Lainez. Buenos Aires: Fondo de Cultura Económica, 2005. 7-36.

Lerner, Isaías. “El unicornio”. Revista Iberoamericana, xxxIII 63 (enero-junio de 1967): 165-167.

Llamas, Ricardo. Teoría torcida. Prejuicios y discursos en torno a "la homosexualidad". Madrid: Siglo xxI, 1998.

Malva. Mi recordatorio. Autobiografía de Malva. Buenos Aires: Libros del Rojas, 2010.

Margulis, Alejandro. Los libros de los argentinos. Entrevistas de Alejandro Margulis. Buenos Aires: El Ateneo, 1998. 
Meccia, Ernesto. Los últimos homosexuales. Sociología de la homosexualidad y la gaycidad. Buenos Aires: Gran Aldea Ediciones, 2011.

Melo, Adrián. Historia de la literatura gay en Argentina. Representaciones sociales de la homosexualidad masculina en la ficción literaria. Buenos Aires: Lea, 2011.

Mérida Jiménez, Rafael M.. “Teorías presentes, amores medievales. En torno al estudio del homoerotismo en las culturas del Medioevo occidental”. Revista de poética medieval 4 (2000): 51-98.

Molloy, Sylvia. “La cuestión del género. Propuestas olvidadas y desafíos críticos”, Revista Iberoamericana 193 (2000): 815-819.

Nasif, Mónica. “El entorno féerico en El unicornio de Manuel Mujica Lainez”. Jornadas de literatura, crítica y medios. Perspectivas 2003 (2003). http://goo.gl/97x0D.

Nogueras, Enrique J.. "Literatura, historia y fantasía en El unicornio de Manuel Mujica Lainez”. L'Edat Mitjana en el cinema i en la novel·a històrica. Eds. Josep Lluís Martos y Marinela Garcia. Alacant: Institut Interuniversitari de Filologia Valenciana, 2009. 475-484.

Peralta, Jorge Luis. "Ediciones Tirso y la difusión de literatura homoerótica en Hispanoamérica”. Lengua, cultura y política en la historia de la traducción en Hispanoamérica. Eds. Francisco Lafarga y Luis Pegenaute. Vigo: Academia del Hispanismo. 191-199.

Prinkey, Troy J. "Discovery of the Self and Authorial 'Outing' of the Protagonist in Manuel Mujica Lainez's 'El retrato amarillo"'. Céfiro: Enlace Hispano Cultural y Literario 2 (2005): 49-55.

Puente Guerra, Ángel. “Manuel Mujica Lainez”. Latin American Writers on Gay and Lesbian Themes. A Bio-Critical Sourcebook. Ed. David William Foster, Westport: Greenwood, 1994. 266-273.

Rodríguez, Félix. Diccionario gay-lésbico. Vocabulario general y argot de la homosexualidad. Madrid: Gredos, 2008.

Rubin, Gayle. "Reflexionando sobre sexo. Notas para una teoría radical de la sexualidad". Placer y peligro. Explorando la sexualidad femenina. Comp. Carole S. Vance. Madrid: Talasa, 1989. 113-190.

Sabsay, Leticia. Fronteras sexuales. Espacio urbano, cuerpos y ciudadanía. Buenos Aires: Paidós, 2011.

Sebreli, Juan José. "Historia secreta de los homosexuales en Buenos Aires”. Escritos sobre escritos, ciudades bajo ciudades. Buenos Aires: Sudamericana. 1997. 275-370.

Sedgwick, Eve Kosofsky. Epistemología del armario.1990. Trad. Teresa Bladé Costa. Barcelona: De la Tempestad, 1998.

Schanzer, George. The Persistence of Human Passions: Manuel Mujica Lainez's Satirical Neo-Modernism. London: Tamesis, 1986.

Soley Beltrán, Patricia. “¿Citaciones perversas? De la distinción sexo-género y sus apropiaciones”. Sexualidades migrantes. Género y transgénero. Ed. Diana Maffía. Buenos Aires: Feminaria, 2003. 59-85.

Vázquez, María Esther. El mundo de Manuel Mujica Lainez. Buenos Aires: De Belgrano, 1983.

Villena, Luis Antonio de. “El país Mujica Lainez”. Antología general e introducción a la obra de Manuel Mujica Lainez. Madrid: Felmar, 1976. 11-33. 
Villordo, Oscar Hermes. Manucho. Una vida de Mujica Lainez. Buenos Aires: Planeta, 1991. Weeks, Jeffrey. Lenguajes de la sexualidad. 2008. Trad. Pablo Betesh. Buenos Aires: Nueva Visión, 2011.

Zangrandi, Marcos. "Infierno, purgatorio y paraíso de Manuel Mujica Lainez". Diario Perfil (2011). http://goo.gl/qhI9N. 